\title{
A CLINICO-PATHOLOGICAL STUDY OF CYSTINOSIS IN TWO SIBLINGS
}

\author{
BY \\ R. J. K. BROWN \\ From the Department of Child Health, Welsh National School of Medicine, Cardiff
}

(RECEIVED FOR PUBLICATION FEBRUARY 18, 1952)

Within recent years a clinical syndrome has emerged which is now recognized as an hereditary disease occurring in children, and probably due to an inborn error of protein metabolism. The earliest symptoms may appear in infancy and include thirst, polyuria, anorexia, vomiting, constipation, thermolability and a tendency to sudden dehydration and toxaemia following trivial infections. As the disease progresses there is stunting of growth, rickets, hepatomegaly and renal damage. Cystine is deposited in the reticuloendothelial system and other tissues and the consequent damage is largely responsible for the varied symptomatology. The disease is often referred to as the syndrome of Fanconi, de Toni and Débré, or as Lignac's disease, but while it is fitting that we pay homage to these authors, the name cystinosis is preferred. Transmission is thought to be by the recessive mode of inheritance and supporting evidence for this is given by the following case reports.

\section{Case Reports}

The parents are first cousins and are themselves healthy. The family pedigree is shown (Fig. 1). There is no family history of renal stones.

Case 1. R.B., a girl and youngest of the three children, was first admitted to Cardiff Royal Infirmary on October 27, 1948, at the age of 1 year and 4 months, because of failure to gain weight. She had been a full term baby, weighing $7 \mathrm{lb} .4 \mathrm{oz}$. at birth, and was breast fed until the age of 7 months, during which time she made good progress. As soon as weaning was begun she gained very little weight, she frequently vomited and became markedly constipated. Solids were so poorly tolerated that she was fed almost entirely on milk feeds. Her weight at the age of 5 months was $17 \mathrm{lb} .8 \mathrm{oz}$. and on admission nearly 12 months later she weighed only $17 \mathrm{lb}$. $12 \mathrm{oz}$. Apart from these feeding difficulties, she was a happy, contented baby, was standing normally and beginning to say a few words. She was, however, thought to have been blind since birth.

She was pale and grossly underweight. She was almost completely blind, but could just appreciate a very bright light. There were no cataracts, but the appearances of the ocular fundi were not recorded. The spleen was palpable and there were numerous hard faecal masses in the abdomen. Otherwise there were no striking abnormalities. No investigations were performed, apart from an intradermal Mantoux test $(1 / 1,000)$ which was negative, and a barium followthrough which revealed no abnormality except delay in the colon caused by faecal masses.

She was fed on a mixed diet and there was no vomiting during her 10 days in hospital, but she failed to gain any weight. During the next 12 months she continued to have a poor appetite and gained weight very slowly.

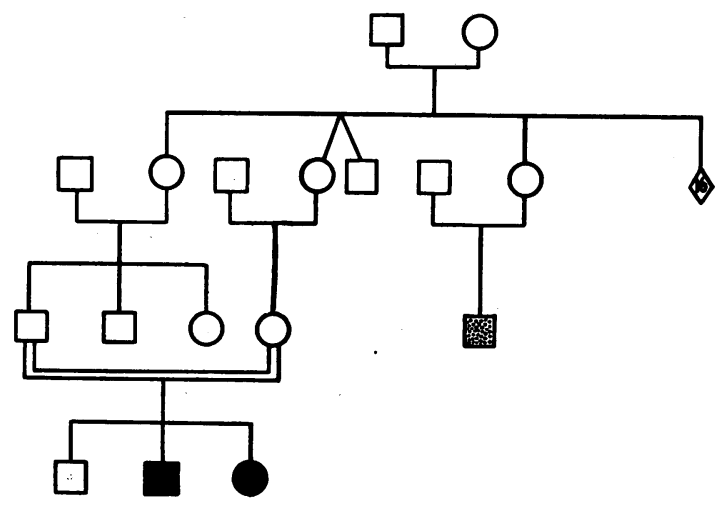

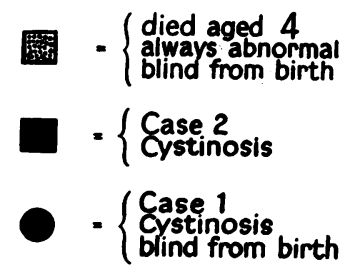

FIG. 1.-Family pedigree. 
On February 14, 1950, she was re-admitted, acutely ill with vomiting and extreme dehydration of very sudden onset. Her temperature was $99: 6^{\circ} \mathrm{F}$., pulse rate 140 per minute, respirations 50 per minute. There was severe gingivitis with bleeding gums, but no sign of infection elsewhere. In spite of intravenous fluids and chemotherapy she died 48 hours after admission. Towards the end her respirations became typically ' acidotic' in character.

Necropsy. The body was somewhat undersized and slightly wasted. Externally the eyes were normal. The skin was dehydrated. The heart showed slight dilatation of the right auricle and ventricle. The trachea contained thick, white, mucopurulent material. Both pleural sacs contained about $50 \mathrm{ml}$. of serous fluid. The lungs were purplish, and the cut surfaces

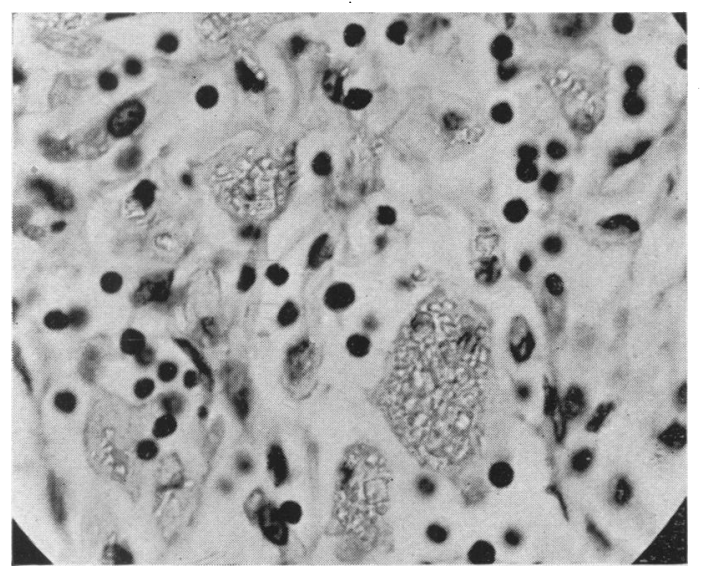

FIG. 2.-Lymph node from Case 1 showing deposits of cystine crystals.

were gelatinous and moderately oedematous. The peritoneal sac contained about $100 \mathrm{ml}$. of serous fluid. In the peritoneal folds of the mesentery there were small nodules of chalky-looking material, which was slightly gritty on section. Minute white dots were visible through the mucosa of the duodenum, but the large intestine and stomach were normal. The liver was enlarged, firm and smooth, with normal contours but of a pale yellowish hue. On the pale background of the cut surface there were minute flecks of white. The spleen was slightly enlarged and its cut surface showed numerous white streaks and dots on a congested background. The lymph nodes in the abdomen were slightly enlarged, and on section a little white stippling was apparent. Similar changes were present in the cervical and bronchial nodes. The bone marrow (femur) was flecked throughout with white opaque material. The capsular surfaces of both kidneys were beset with numerous minute pale dots: the cut surfaces showed irregular fine white streaking and punctation of a generally pale parenchyma affecting both the cortex and the medulla. The skull appeared normal and the femur examined showed no evidence of rickets.
Microscopical examination of sections had not been made when Case 2 was diagnosed as cystinosis. Confirmatory evidence of the same disease was now diligently sought in this necropsy material, and the positive findings were as follows:

There was mild subacute lymphadenitis in the cervical lymph node. In the sinusoids, chiefly within the medulla, there were collections of large mononuclear macrophages containing clusters of doubly refractile crystals (Fig. 2).

In the lungs there was moderately severe oedema with congestion and a few foci of minimal inflammatory exudation.

There was a severe degree of fatty change in the liver. No crystals were detected.

The pulp of the spleen was hyperplastic and congested, and throughout there were ill-defined accumulations of proliferating reticulo-endothelial cells, many containing clusters of doubly refractile crystals.

The general architecture of the kidney was somewhat disorganized. In the cortex the glomeruli were crowded as a result of widespread atrophy of intervening tubules and early stromal proliferation. Some of the glomeruli were becoming hyalinized. Many of the surviving cortical tubules were dilated and tortuous, lined by redundant low cuboidal epithelium and filled with albuminous debris or casts. In the medulla there was similar loss of tubules and fibrous replacement, the residual tubules being somewhat distended and lined by irregular epithelium. The pelvis was normal. Scanty doubly refractile crystals were present, some in the lumen of the tubules in the medulla and some in the interstitial tissues.

In the small intestine there was proliferation of macrophages in some villi, the cells being filled by clusters of doubly refractile crystals.

The doubly refractile crystals found in various organs were morphologically similar to those of cystine. As the nature of the condition was not recognized at necropsy, prolonged fixation seemed to have resulted in the disappearance of crystals from the liver and to a large extent from the kidneys.

Case 2. D.B., a boy and second of the three children, was first admitted to Cardiff Royal Infirmary on August 22, 1947, aged 1 year and 10 months, because of severe anorexia and constipation, which had been present for seven months. He had also been passing an unusually large quantity of strongly ammoniacal urine. He had been a full term baby weighing $6 \mathrm{lb}$. $10 \mathrm{oz}$. at birth, and had been entirely breast fed. He had been severely ill for two months after contracting whooping cough in April, 1947, but apart from this had had no previous illness.

On examination he was found to have slight enlargement of the liver and the spleen and there were numerous knobbly faecal masses in the abdomen. His urine reduced Benedict's solution on one occasion, but subsequent examinations failed to confirm this. The intradermal Mantoux test $(1 / 1,000)$ was negative; haemoglobin was $9.0 \mathrm{~g} . \%(=62 \%)$ and leucocytes 12,000 per c.mm. with $78 \%$ polymorphs. He received 
enemata for his constipation and returned home improved on September 4.

Within a very short time his symptoms recurred and he was re-admitted on September 17, 1947. It was noted that his urine was usually alkaline, that it contained a moderate amount of albumin and that some specimens reduced Benedict's solution: there were occasional hyaline and granular casts, a few pus cells, and cultures produced a moderate growth of coliform organisms. Haemoglobin was 10.0 g. $\% \quad(=69 \%)$; leucocytes 14,400 per c.mm. with $56 \%$ polymorphs; blood sugar $107 \mathrm{mg}$. per $100 \mathrm{ml}$. A barium enema suggested a mild megacolon.

He remained in hospital until October 10, and during this period his appetite was poor but he was always very thirsty. The full significance of the thirst and urinary findings was not appreciated at this time, and attention was focussed on the constipation, which was treated with petrolagar.

On October 3, 1948, now aged 3 years, he was readmitted for dental extractions. At this time his most prominent symptom was polyuria; he was passing urine almost hourly. His bowels were still constipated but his appetite had improved. He appeared to be about the normal height for his age. He was pale, the abdomen was prominent and the liver and spleen still enlarged. He had a large head, a mouth full of carious teeth and severe genu valgum (Fig. 3). Radiographs of the bones showed no evidence of rickets.

After this he was seen regularly as an outpatient. His general condition very gradually deteriorated. Constipation and polyuria continued. He was becoming obviously dwarfed and the knockknee deformity was increasing. Walking irons had been supplied without very much benefit. In May, 1951, radiographs revealed evidence of active rickets for the first time: severe rachitic changes were present at the upper and lower ends of both femora and minimal changes at the wrists.

In view of the rickets he was re-admitted for further investigation on June 7,1951 . He was now nearly 6 years old, and an intelligent, fair-haired boy with blue eyes, a large head, and a 'saddle' depression of the bridge of the nose. The abdomen was protuberant, there was marked genu valgum and generalized hypotonia. He was very undersized (height, $3 \mathrm{ft} .2$ in.; weight, $28 \mathrm{lb}$.). He was pale and the skin had a faint icteric tinge. A tendency to screw up the eyes sug-

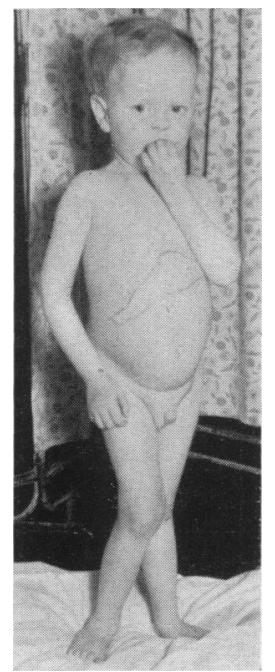

FIG. 3.-Case 2: note genu valgum. gested photophobia. Many remaining teeth were carious. In the abdomen a firm, smooth liver was enlarged two fingerbreadths below the costal margin, but the spleen was not palpable. No other abnormality was found; the heart was not enlarged and the blood pressure was
$85 / 60$. Radiographs, in addition to showing rickets, revealed a bone age of between 3 and 4 years. A review of his condition, together with a perusal of his previous

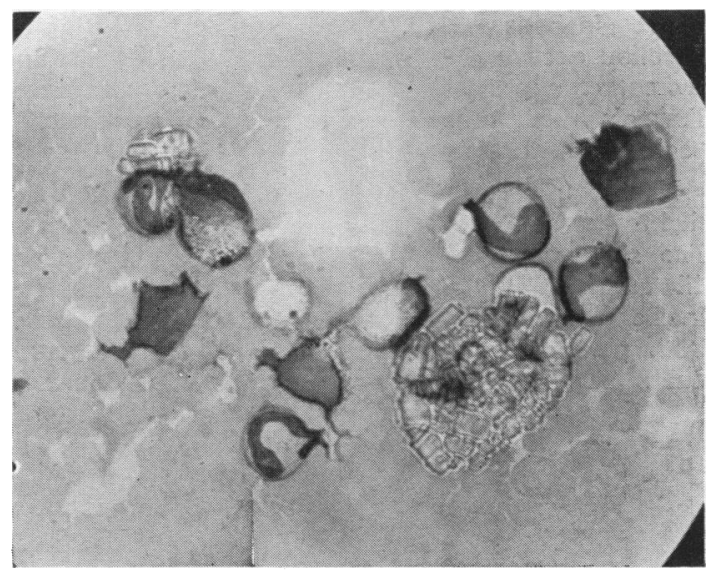

FIG. 4.-Cystine crystals in marrow smear from Case 2.

inpatient records, suggested a diagnosis of cystinosis. The main points were the early feeding difficulties, severe constipation, polyuria and polydipsia, intermittent glycosuria and persistent albuminuria. Confirmation was obtained by slit-lamp microscopy when the typical cystine crystals could be seen in the cornea, and cystine crystals were also found in material from marrow puncture (Fig. 4).

Partition paper chromatography revealed a typical pattern of amino-acids in the urine (Fig. 5).

A blood count gave haemoglobin $6.4 \mathrm{~g} . \%(=46 \%)$. The red cells were mildly hypochromic and microcytic. The blood urea level was $131 \mathrm{mg}$. per $100 \mathrm{ml}$.

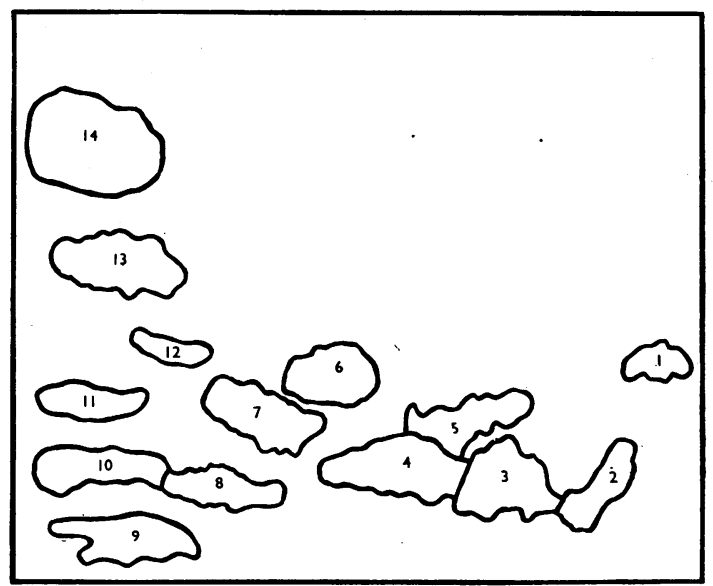

FIG. 5.-Tracing of amino-acid chromatogram of urine from Case 2 showing excessive excretion of amino-acids.

1, cysteic acid; 2, aspartic acid; 3, glutamic acid; 4, glycine; 5, serine; 6, threonine; 7 , alanine; 8 , glutamine; 9, lysine; $10, \gamma-$ amino-iso-butyric acid; 11, proline; 12, a-amino-iso-butyric acid; 13, valine; 14, leucine. 
The urine was usually alkaline, with persistent albuminuria, and red cells and occasional hyaline and granular casts in the deposit. There was no reduction of Benedict's solution, but paper chromatography revealed excretion of glucose and fructose. The daily output averaged $48 \mathrm{oz}$. and the specific gravity was never above $1 \cdot 010$.

The serum bilirubin level was $3 \mathrm{mg}$. per $100 \mathrm{ml}$., the serum calcium $8.8 \mathrm{mg}$. per $100 \mathrm{ml}$., the serum inorganic phosphate $5.5 \mathrm{mg}$. per $100 \mathrm{ml}$. and the serum alkaline phosphatase 62 units.

The thymol turbidity test gave 3 units, and the Kunkel test 3 units.

The plasma $\mathrm{CO}_{2}$ combining power varied between 48 and $64 \mathrm{vol}$. \%. The plasma potassium (by flame photometer) was $3 \cdot 1 \mathrm{mEq}$ /litre (normal 3.75-5).

The amino-acids excreted in the urine determined by microbiological assay were in most cases 10 times the normal values, as are shown below.

\begin{tabular}{|c|c|c|c|}
\hline Amino-Acid & $\begin{array}{l}\text { Concentrations } \\
\text { (mg./100 ml.) }\end{array}$ & $\begin{array}{c}\text { Approximate } \\
\text { Daily Output } \\
\text { (mg.) }\end{array}$ & $\begin{array}{l}\text { Daily Output } \\
\text { in } \\
\text { Normal Child } \\
\text { (mg.) }\end{array}$ \\
\hline $\begin{array}{ll}\text { Valine .. } & \ldots \\
\text { Arginine } & \ldots \\
\text { Threonine } & \ldots \\
\text { Phenyl-alinine } & \ldots \\
\text { Tryptophane } & \ldots\end{array}$ & $\begin{array}{r}10 \\
6 \\
15 \\
10 \\
2 \cdot 5\end{array}$ & $\begin{array}{l}150 \\
90 \\
225 \\
150 \\
37 \cdot 5\end{array}$ & $\begin{array}{l}15 \\
20 \\
14 \\
12 \\
15\end{array}$ \\
\hline
\end{tabular}

The child also exhibited characteristic thermolability, as a specimen temperature chart shows very clearly (Fig. 6).

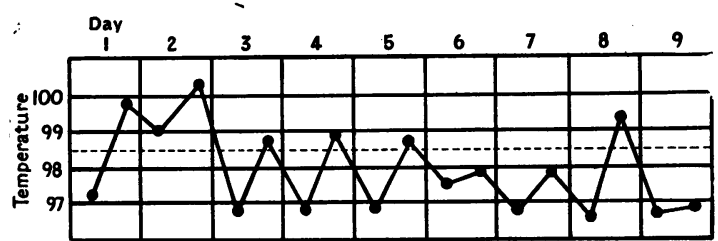

FIG. 6.-Specimen temperature chart from Case 2 showing somewhat unstable temperature.

He was given a high protein, high calcium diet, and additional calcium was also supplied as calcium phosphate in a dose of $1 \mathrm{~g}$. daily. Calciferol was administered in large dosage $(100,000$ units daily). Albright's citric acid-sodium citrate buffer mixture (citric acid $60 \mathrm{~g}$.; sodium citrate $100 \mathrm{~g}$; ; aqua ad 1,000 ml.) was given, beginning with a daily dose of $45 \mathrm{ml}$. and gradually increasing, with frequent estimations of the $\mathrm{CO}_{2}$ combining power as a check, until the present dose of $120 \mathrm{ml}$. was reached.

It has been found that with a high calcium intake and large doses of 'calciferol' healing of the rickets can be obtained. Frequent estimations of the serum alkaline phosphatase are necessary, as it is recommended that the calciferol dosage be reduced to $30-50,000$ units daily as soon as the phosphatase reaches a normal level (Bickel, personal communication). The citrate therapy seemingly assists in the process of healing. There may be a synergistic action, for rickets does not heal well
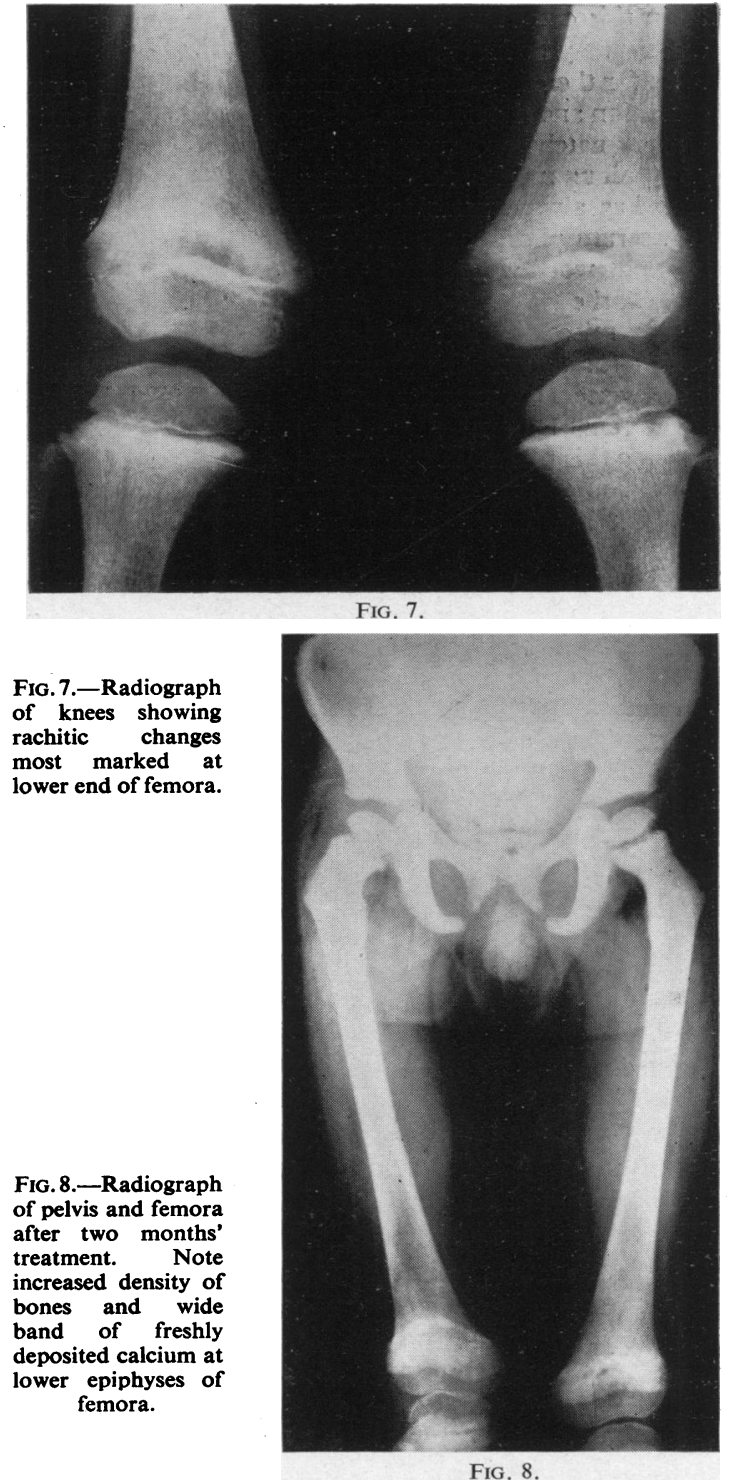

in the presence of acidosis. Recently healing of vitamin $D$ deficiency rickets by the administration of citrates alone has been recorded (Eliot and Park, 1951). The main objects of citrate therapy are to combat acidosis and lessen the degree of amino-aciduria. Since cystine is soluble in alkali it is hoped that excess of it will be excreted in solution and its retention be prevented. It should be noted, however, that Gittleman and Pincus (1940) gave the citric acid-sodium citrate buffer mixture to their patient for three months without improvement, though it may be objected that their dosage was small and they did not continue the administration long enough. In any event it is difficult to imagine any dramatic improvement once irreversible damage has occurred, 
as in this case, but it is hoped that the progress of the disease may be halted.

So far there has been some improvement in his general condition and the rickets has begun to heal (Fig. 7 and 8). Unfortunately, we suspect severe renal damage, since gross albuminuria and cylinduria persist and the blood urea has always remained above $100 \mathrm{mg}$. per $100 \mathrm{ml}$. The serum phosphorus level is also relatively high, and it is noteworthy that in the review of McCune, Mason and Clarke (1943) the blood urea level was only significantly raised in those cases showing relatively high values for serum phosphorus: in other words, where ithe disease had progressed to produce hyperphosphataemic renal rickets. As further evidence of severe renal damage this patient has a chronic anaemia which has not responded to iron by mouth or intravenously, and for which blood transfusions have had to be given every few weeks.

On October 3, 1951, the blood urea was $113 \mathrm{mg}$. per $100 \mathrm{ml}$., $\mathrm{CO}_{2}$ combining power 62 vol. \%, serum alkaline phosphatase 21 units and serum calcium $12.4 \mathrm{mg}$. per $100 \mathrm{ml}$., and at this stage the dose of 'calciferol' was reduced to 50,000 units daily.

Apparently, hypokalaemia is a feature of some cases, in which event cautious treatment with potassium salts is beneficial (Bickel; personal communication), but the need for such treatment has not arisen in this case.

\section{Discussion}

Rare hereditary disorders are always a source of interest, and perhaps few of them have captivated the imagination so much as cystinosis. The widespread pathology necessarily means that the clinical manifestations are protean, and considerable variations of the classical clinical picture will occur, depending on the degree of damage in any particular organ and the age of the patient.

These two case histories illustrate very well how the disease may present itself in infancy and in the older child. We may compare the disease in infancy with the idiopathic infantile renal acidosis (nephrocalcinosis) of Lightwood (1935) and Payne (1948), and it is suggested that in all cases the possibility of "cystinosis should be considered. Estimation of amino-acids in the urine by paper chromatography must be made before treatment with a citrate mixture is begun since the latter tends to abolish amino-aciduria. Any unusual case of rickets ought to be similarly investigated. Where glycosuria is a marked feature it may be tempting to perform a glucose tolerance test, but great care must be exercised, since the administration of large doses of glucose has been known to produce a dangerous state of shock in these patients (Fanconi, 1936), and proved fatal in one instance (Debré, Marie, Cléret and Messimy, 1934).

The diagnosis of cystinosis should not be difficult if the condition is borne in mind and the symptom complex is considered as a whole. It has been shown in these case histories how the true nature of the malady may be obscured by such incomplete diagnoses as feeding difficulties or mild megacolon. The discovery that cystine crystals can be seen in the cornea by slit-lamp microscopy (Bürki, 1941) has provided a convenient diagnostic test; similarly, the finding of cystine crystals in the marrow smears is diagnostic (Esser, 1941). More recently partition paper chromatography has been shown to be a most valuable aid in the diagnosis and investigation of the disease (Dent, 1947).

The disease is apparently quite unrelated to cystinuria, whether this be symptomless or associated with calculus formation. The question has been lately clarified by Dent and Rose (1951), who have brought forward very convincing evidence to show that cystinuria is not due to an inborn error of metabolism as first propounded by Garrod (1923), but results from a low renal threshold due to a defective reabsorption by the renal tubules. The amino-acids, cystine, lysine and arginine, are excreted in excess in the absence of any increase in the plasma levels of these or any other aminoacids. On the contrary, in cystinosis the excretion of cystine forms but a part, and often an insignificant part, of a generalized amino-aciduria. Indeed, were the two conditions manifestations of the same disease process, one would expect to find them closely associated genetically, and this is not so. In the first published account of cystinosis (Abderhalden, 1903) a strong family history of cystinuria is claimed, but subsequent reports have not brought confirmation of any close link between the two conditions.

Further confusion has arisen from attempts to separate cystinosis or Lignac's disease (Lignac, 1924) from the de Toni-Fanconi syndrome. To quote Freudenberg (1949):

- The clinical pictures of cystinosis and the de Toni-Fanconi -syndrome are almost identical, but there are some cases of the syndrome in which neither the excretion of cystine nor its presence in the tissues has been proved. The question arises therefore whether there may not be cases of the syndrome in which the aetiology is different from that of cystinosis.'

Fuller investigation with newer techniques, such as paper chromatography, is tending to bring these syndromes into line with one another, and Fanconi himself has suggested that cystinosis is a more exact appellation for all such cases (Fanconi, 1946).

A striking similarity exists between the clinical picture of idiopathic renal acidosis of infancy (nephrocalcinosis) and the earliest stages of cystinosis. The mechanism of the former condition 
has been explained on the basis of an assumed defect in the proximal renal tubules whereby there is impaired absorption of bicarbonate (Latner and Burnard, 1950). It is tempting to postulate that the tubular damage which is known to take place in cystinosis is similarly responsible for the production of a renal acidosis even in the early stages of the disease, for the accumulation of amino-acids in the blood stream will not cause acidosis and one must look elsewhere for an explanation of this symptom.

The pathogenesis of many other features awaits complete elucidation, and with the progress of research into this disease many current views will require alteration.

While adding little or nothing to existing knowledge of the disease process itself, these case histories do provide another link in the chain of evidence accumulating to prove its hereditary nature and its transmission as a recessive Mendelian characteristic. On this assumption it is easy to see why the disease is rare, and it is not surprising that a consanguineous marriage may result in more than one affected child, since both parents are likely to be carriers. The parents were first cousins in de Toni's case (1933) and Fanconi's second case (1936), and consanguinity was suspected in Fanconi's third case (1936). In the patient described by McCune, Mason and Clarke (1943) the parents were second cousins once removed. The nature of the congenital blindness which figures twice in this pedigree is not known but it may well be a further hereditary

\section{Addendum}

Since this article was submitted for publication, D.B. has unfortunately died. He was admitted in an advanced state of uraemia on April 7, 1952. His final illness was characterized by severe vomiting, watery diarrhoea and convulsions. Treatment was unavailing and in less than a month he had lapsed into coma and died. Terminally the blood urea reached a level of $468 \mathrm{mg}$. per $100 \mathrm{ml}$. A post-mortem examination performed by Dr. R. A. Parker revealed very early miliary tuberculosis. The changes of cystinosis were also abundantly evident and the kidneys trait: it is unlikely that cystine deposits in the uveal tract could be sufficiently extensive at birth to cause blindness.

\section{Summary}

Two examples of the rare hereditary disorder of cystinosis are recorded.

Necropsy findings are given in the one fatal case.

As the two patients were siblings and the parents first cousins, further evidence in favour of the recessive mode of transmission is provided.

Thanks are due to Professor A. G. Watkins for permission to publish these case reports and for his encouragement and advice; to Dr. H. Bickel who performed many of the investigations, including the chromatography, and was always ready to give helpful advice, and to Dr. L. L. R. White who supplied the necropsy report.

\section{REFERENCES}

Abderhalden, E. (1903). Hoppe-Seyl. Z. physiol. Chem., 38, 557.

Bickel, $H$. Personal communication.

Bürki, E. (1941). Ann. paediat., Basel, 156, 324.

Debré, R., Marie, J., Cléret, F. and Messimy, R. (1934). Arch. Méd. Enf., 37, 597.

Dent, C. E. (1947). Biochem. J., 41, 240.

- and Rose, G. A. (1951). Quart. J. Med., 20, 205.

De Toni G. (1933). Acta paediat. Uppsala, 16, 479.

Eliot, M. M. and Park, E. A. (1951). Brennemann's Practice of Pediatrics, ed. McQuarrie, I., Vol. I, ch. 36, p. 107. Hagerstown, Maryland.

Esser, M. (1941). Ann, paediat., Basel, 156, 344.

Fanconi, G. (1936). Jb. Kinderheilk., 147, 299.

- (1946). Helv. paediat. Acta., 1, 183.

Freudenberg, E. (1949). Advanc. Pediatr., 4, 265.

Garrod, A. E. (1923). Inborn Errors of Metabolism, 2nd ed. London.

Gittleman, I. F. and Pincus, J. B. (1940). Amer. J. Dis. Child., 60, 1351 .

Latner, A. L. and Burnard, E. D. (1950). Quart. J. Med., 19, 285.

Lightwood, R. (1935). Archives of Disease in Childhood, 10, 205.

Lignac, G. O. E. (1924). D Dtsch. Arch. k.in. Med., 145, 139.

McCune, D. J., Mason, H. H. and Clarke, H. T. (1943). Amer. J.

Dis. Child., 65, 81. Archives of Disease in Childhood, 23, 145.

were markedly fibrotic with much calcification in the tubules and glomeruli.

I am indebted to Dr. Percy Bray for the following additional information about this family. Mrs. B. (mother of D.B. and R.B.) gave birth to heterozygous twins on June 13, 1952. They were rather feeble at birth but were progressing satisfactorily on discharge from hospital. Urine specimens collected during the first week revealed, on chromatography, a physiological pattern of aminoacids in the female infant and no amino-aciduria in the male. The tests are to be repeated when the infants are 3 months old. 